\title{
Circulação de Ideias e Apropriações Culturais na Diáspora Negra
}

\section{Circulation of Ideas and Cultural Appropriation in the Black Diaspora}

\author{
Maria Angélica Zubaran ${ }^{1}$ \\ Juliana Ribeiro de Vargas $^{2}$
}

Resumo Este artigo investiga o intercâmbio e a circulação de ideias na diáspora negra, particularmente no jornal O Exemplo, mapeando e problematizando as representações étnico-raciais e de gênero construídas nas narrativas produzidas pelos redatores desse jornal por ocasião da campanha para a construção do monumento à "Mãe Preta". Busca-se analisar de que forma os redatores do jornal se apropriaram de textos que circularam em outros jornais sobre a campanha ao monumento da "Mãe Preta", adaptaram-nos aos seus próprios interesses e lhes atribuíram novos significados. A partir da abordagem teórica dos Estudos Culturais, entende-se a imprensa negra como um artefato cultural que não apenas informa, mas que também produz discursos e representações que contribuem na formação de subjetividades e identidades negras.

Palavras-chave: Apropriações culturais; Representações étnico-raciais; Imprensa negra

Abstract This paper investigates the exchange and circulation of ideas in the black diaspora, particularly in the newspaper The Example, mapping and discussing the ethnic-racial and gender representations constructed in the narratives produced by the editors of this newspaper, during the campaign for the construction of a monument to the "Black Mother". The aim is to analyze how the

\footnotetext{
${ }^{1}$ Universidade Luterana do Brasil - Ulbra, Canoas, RS, Brasil.

E-mail: angelicazubaran@yahoo.com.br

2 Universidade Luterana do Brasil - Ulbra, Canoas, RS, Brasil.

E-mail: julivargas10@hotmail.com
} 
32 CIRCULAÇÃO DE IDEIAS E APROPRIAÇÕES CULTURAIS NA DIÁSPORA NEGRA

newspaper's editors have appropriated texts that circulated in other newspapers about the campaign to the monument of the "Black Mother", adapted them to their own interests and given them new meanings. From the theoretical approach of Cultural Studies, we understand the black press as a cultural artifact that not only informs but also produces discourses and representations that contribute to the formation of black subjectivities and identities.

Keywords: Cultural Appropriations; Ethnic-Racial Representations; Black Press 
Este estudo investiga o intercâmbio e a circulação de ideias na diáspora negra no jornal de imprensa negra O Exemplo, de Porto Alegre, por ocasião da campanha para a construção de um monumento à "Mãe Preta" na década de 1920. Está constituído em uma perspectiva interdisciplinar que articula os campos teóricos dos Estudos Culturais e da História Cultural e, em termos metodológicos, trata-se de uma análise cultural que opera com os conceitos de apropriação cultural e representação.

Na perspectiva da História Cultural, utilizamo-nos do conceito de apropriação cultural, na direção apontada por Roger Chartier (2002), para compreender os processos de construção de significados atribuídos aos textos culturais, os quais, segundo o referido autor, não são absolutos ou únicos, mas estão relacionados às diversas formas como diferentes sujeitos interpretam os textos que leem e aos múltiplos sentidos e significados que lhes atribuem, tornando possível reapropriações, contestações ou resistências. Nesse sentido, buscamos avaliar de que forma os redatores do jornal O Exemplo se apropriaram de textos que circularam em outros jornais sobre a construção do monumento à "Mãe Preta”, adaptaram-nos aos seus próprios interesses e lhes atribuíram outros significados.

A partir da abordagem teórica dos Estudos Culturais, apropriamo-nos das discussões de Stuart Hall (2000) sobre representação. Para o autor, as representações culturais contidas na linguagem não apenas "falam sobre", mas constituem as coisas sobre as quais falam, uma vez que as coisas não possuem um significado intrínseco, essencial. Ante essa assertiva, podemos depreender que construímos os significados daquilo que nos cerca utilizando sistemas de representação. Dessa forma, destacamos que o estudo aqui realizado visa, portanto, investigar o poder das representações no jornal O Exemplo.

Quanto ao processo de codificação e decodificação da linguagem, também Hall (1995) apresenta três posições de recepção ou de decodificação: o modo hegemônico, no qual a decodificação do receptor é equivalente à codificação do emissor; o modo negociado, que modifica, em parte, as significações pretendidas pela cultura hegemônica: o receptor aceita a definição veiculada pela mensagem, mas a adapta 
localmente e até se opõe a ela parcialmente; e o modo oposicional, que cria significações contrárias às veiculadas pela cultura dominante. Conforme Éric Maigret (2010), Hall rejeita a ideia de uma correspondência entre o momento da produção e o da recepção das mensagens midiáticas e não vê razão para que uma mensagem seja automaticamente decodificada como foi codificada. É nessa direção teórica, das diferentes posições de recepção ou de decodificação da cultura dominante, que desenvolvemos, neste estudo, a análise da circulação de ideias e trocas culturais na imprensa negra. Portanto, como já apontamos, pretende-se examinar como os articulistas do jornal O Exemplo decodificaram os textos sobre a "Mãe Preta" que circularam na imprensa do centro do país.

\section{Intercâmbio de ideias na imprensa negra}

Destacamos que a circulação de ideias entre a imprensa negra dos EUA, a grande imprensa carioca e a imprensa negra brasileira em torno de questões étnico-raciais no início do século XX foi analisada por autores como Santos (2011), Seigel (2007), Alberto (2011) e Pereira (2013). Santos (2011), a partir das discussões em torno da diáspora africana, argumenta que, na década de 1920, os redatores da imprensa negra meridional estabeleceram trocas transnacionais com a imprensa negra norte-americana, com troca de exemplares do Chicago Defender, dos EUA, por O Clarim da Alvorada, de São Paulo. Nessa mesma direção, Pereira (2013, p. 149) aponta que "a partir de 1920 e também na década de 1930, a circulação de informações na diáspora negra se ampliou muito". De acordo com o autor, a década de 1920 foi um momento de grande intercâmbio cultural entre a imprensa negra afro-americana e a afro-brasileira, momento em que os norte-americanos olharam com interesse para as relações raciais no Brasil e, ao mesmo tempo, trocaram referências sobre a luta contra o racismo.

Nessa direção, Seigel (2007) e Alberto (2011) destacaram que, no início do século XX, a imprensa brasileira se transformou em um espaço de apropriações e debates intensos, sendo visível a sua importância no que concerne à circulação de ideias. Seigel (2007), a partir de uma 
perspectiva transnacional, investigou o intercâmbio de informações ocorrido por ocasião da campanha do monumento à "Mãe Preta" no Brasil, na década de 1920, analisando as trocas culturais entre a imprensa afro-americana do Chicago Defender e os jornais brasileiros A Notícia (RJ) e O Clarim da Alvorada (SP). De acordo com o referido autor, a proposta da construção de um monumento à "Mãe Preta" começou nos EUA, quando "as daughthers of the American Confederacy (filhas dos confederados norte-americanos) propuseram a construção de uma estátua para a Mammy na capital dos Estados Unidos" (Seigel, 2007, p. 314). A autora aponta que, quase três anos depois, em 1926, a campanha se estendeu para a imprensa do Rio de Janeiro, no jornal A Notícia, por intermédio de seu redator Cândido de Campos, que passou a defender a construção de um monumento à "Mãe Preta" como forma de celebrar a mistura racial que, no Brasil, teria contribuído para o caráter específico de fraternidade racial na formação da identidade nacional brasileira.

Segundo a autora, a partir do jornal A Notícia, a proposta foi encampada por José Correia Leite, fundador e editor do jornal da imprensa negra paulista O Clarim da Alvorada, e, graças a Robert Abott, editor do jornal afro-americano Chicago Defender, a campanha para a construção de um monumento à "Mãe Preta" no Rio de Janeiro e em São Paulo também repercutiu no exterior, "assinalando a diferença marcante entre a harmonia racial brasileira e o antagonismo racial norte-americano" (SEIGEL, 2007, p. 332). Na esfera da imprensa negra paulista, a autora sublinha que "os escritores afro-brasileiros acharam o discurso da fraternidade nacional apropriado às suas reivindicações de uma cidadania inclusiva [...] e a empregaram numa direção antirracista" (SEIGEL, 2007, p. 325). Por fim, a autora conclui que a campanha realizada no Brasil para a construção de um monumento à "Mãe Preta" nos anos 1920 contribuiu para mudar o discurso sobre raça no país, adotando a retórica da harmonia racial uma década antes de Gilberto Freyre. No entanto, Seigel (2007) argumenta que, no período da Revolução de 1930, a mobilização pela construção do monumento foi abandonada e a ideia só foi retomada no início dos anos 1950, quando o monumento à "Mãe 
Preta" foi inaugurado no largo do Paissandú, no centro da cidade de São Paulo, junto à igreja da Nossa Senhora do Rosário, transformando-se em um ponto de referência para a comunidade negra paulista.

Já Alberto (2011), em sua tese de doutorado, depois publicada em livro intitulado Terms of Inclusion: Black Intellectuals in Twentieth-Century Brazil, argumentou que os proponentes brancos da estátua da "Mãe Preta" no Rio de Janeiro ecoaram reformulações nacionalistas da identidade nacional e publicamente defenderam uma identidade nacional misturada em 1926. Na mesma direção apontada por Seigel (2007), a autora também defende que a campanha do monumento à "Mãe Preta" foi o começo de uma importante mudança na forma como a elite brasileira pensava sobre raça, tornando possível imaginar os afrodescendentes como parte integral da nação. Ademais, ela argumenta que o monumento era um tributo ao ideal popular de fraternidade racial.

Alberto (2011) argumenta que, enquanto os jornalistas brancos defenderam a noção de tolerância racial e elogiaram a passividade da "Mãe Preta", os jornalistas da imprensa negra paulista usaram a ideia da construção do monumento para destacar simbolicamente as contribuições dos negros à nacionalidade. Segundo a autora, tanto a ideia de distintas raças, a branca e a negra, como o ideal da mestiçagem foram estratégias políticas encaminhadas pelas lideranças negras paulistas com o objetivo de afirmar o pertencimento dos brasileiros negros a uma nação racialmente e culturalmente inclusiva e, ao mesmo tempo, preservar seus direitos a uma identidade distinta como negros descendentes de africanos. Para Alberto (2011, p. 120), “juntas essas ideias ajudaram os afrodescendentes a encontrar espaços de inclusão e a denunciar o persistente racismo". A partir dessas análises, apresentamos o seguinte questionamento: como as ideias disseminadas por ocasião da campanha para a construção de um monumento à "Mãe Preta” nos jornais A Notícia, do Rio de Janeiro (RJ), e O Clarim da Alvorada, na imprensa negra paulista, foram apropriados pelas lideranças do jornal O Exemplo? Antes de contemplar essa questão, organizamos uma breve apresentação do jornal O Exemplo para contextualizar a sua importância na comunidade negra porto-alegrense. 


\section{O jornal $O$ Exemplo (1892-1930)}

O Exemplo foi o primeiro impresso da comunidade negra de Porto Alegre (RS), produzido por um grupo de jovens negros que se reunia em uma barbearia situada na rua dos Andradas, no centro da cidade. Esse grupo de afrodescendentes que deu início ao jornal era composto por Arthur de Andrade, Marcílio Freitas, Aurélio Bittencourt Júnior, Sérgio Bittencourt, Alfredo de Souza e Esperidião Calisto.

Conforme apontou o poeta e militante negro Oliveira Silveira, o jornal O Exemplo manteve, com algumas interrupções, uma trajetória de 37 anos de publicação (1892-1930) dedicada à comunidade negra e aos populares. ${ }^{3}$ Ante este dado, entendemos que o jornal representou um espaço alternativo de produção de significados e de representações sobre as memórias e identidades afrodescendentes no Rio Grande do Sul, onde seus redatores reafirmaram suas memórias coletivas e suas práticas sociais e culturais. Portanto, como portador de referências às memórias e identidades afro-brasileiras, o jornal O Exemplo constitui um importante patrimônio cultural afro-brasileiro. Sobre o formato e a periodicidade do jornal, Zubaran (2008, p. 166) afirma que:

Era um jornal semanal, de quatro páginas, que saía aos domingos, de tiragem modesta e vendido pelos próprios editores na sede do jornal ou através de assinaturas semestrais. Após alguns anos de existência, no final do século XIX, entre 1892 e 1897, O Exemplo voltou a circular no início do século XX, em 5 de outubro de 1902 e manteve-se em atividade até 1905. Após um período de interrupção, reapareceu em 1908 e se manteve em circulação até 1911. A última fase se inicia com seu reaparecimento em 1916 e se encerra definitivamente em 1930.

Quanto à receptividade desse jornal pela população negra, podemos afirmar que ele funcionava por meio de assinaturas e também contava com o suporte do chamado "grupo mantenedor", o qual usava seus próprios recursos financeiros, quando necessário, para a manutenção do jornal. Considerando-se o tempo de circulação do referido jornal,

\footnotetext{
${ }^{3}$ Manuscritos de Oliveira Silveira sob a guarda de sua filha, Naiara Oliveira Silveira.
} 
aproximadamente 37 anos, entende-se que ele tinha receptividade significativa na comunidade negra.

Desta forma, compreendemos o jornal O Exemplo como uma fonte de pesquisa de extrema relevância para o estudo das memórias, da história e da cultura afro-brasileira na perspectiva da lei 10.639/2003 e da ampliação das políticas de preservação do patrimônio. Conforme apontou Pelegrini (2007), a partir da segunda metade do século XX, houve o paulatino alargamento das noções de patrimônio cultural, que passaram a abranger as memórias de amplos segmentos sociais, particularmente de grupos e etnias minoritários, cujos bens culturais eram anteriormente excluídos do rol dos patrimônios culturais dignos de preservação.

\section{Circulação de ideias e trocas culturais no jornal 0 Exemplo}

A presente análise pretende demonstrar o intercâmbio cultural e a circulação de ideias entre o jornal O Exemplo e jornais do centro do país e mapear as representações étnico-raciais e de gênero mais recorrentes construídas nas narrativas produzidas pelos redatores desse jornal na ocasião da campanha para a construção do monumento à "Mãe Preta", na década de 1920. Particularmente, trata-se de investigar as múltiplas apropriações culturais e pedagogias culturais que os jornalistas afrodescendentes fizeram circular no jornal.

Em artigo intitulado "Mãe Preta”, publicado n'O Exemplo em maio de 1926, o redator Mário Rodrigues apoiava a campanha iniciada no jornal A Notícia, do Rio de Janeiro, e cumprimentava o jornalista Cândido de Campos pela iniciativa, demonstrando o intercâmbio de ideias entre o jornal carioca e O Exemplo. Em sua narrativa, Mário Rodrigues representava a "Mãe Preta" como "um tipo abnegado", cujos gestos e atitudes emanavam uma "paciência heroica”, um "exemplo de resignação e doçura”, de “pureza e altruísmo”, um “império de fidelidade”.

${ }^{4}$ O Exemplo, 26 de maio de 1926, p. 1. 
Também o redator Leandro Pierini, em artigo intitulado "Mãe Preta", de maio de 1928, mantinha a representação doce e submissa que circulou no jornal A Notícia. De acordo com Pierini, "Conseguiremos esse desideratum, não há dúvida, concretizaremos no bronze ou no granito eterno a figura amorosa e submissa da Mãe Preta”. Nesse sentido, na direção apontada por Hall (1997), as representações da "Mãe Preta", embora idealizadas, permaneciam estereotipadas na imprensa negra porto-alegrense, pois persistiam as imagens de humildade, bondade e submissão típicas da representação do "nobre selvagem" veiculada desde o final do século XIX e reiteradas nos romances e filmes norte-americanos no século XX. Por outro lado, essas representações racializadas da "Mãe Preta" não apenas a definiam em termos de suas características essenciais, mas também a reduziam à sua essência, à submissão e fidelidade às famílias de seus senhores e senhoras brancas, conforme se observa na narrativa que segue:

No lar era ela a paciência e a bondade. Tinha pela família a quem pertencia apego e amor, pelo sinhô moço ou pela sinhazinha desvelos frementes e cálidos anseios, próprios de mãe legítima e a eles dedicava-se com a submissão resignada e reverente dos seres afetivos e simples. ${ }^{5}$

Além de naturalizar o trabalho submisso e subserviente da "Mãe Preta" e de apresentar como natural o fato de ela servir aos senhores brancos, o narrador constrói um cenário de relações raciais fraternas entre a "Mãe Preta" e seus senhores, escamoteando as hierarquias de poder que marcaram essas relações, como demonstrado pela recente historiografia sobre a escravidão no Brasil. No excerto a seguir, pode-se observar que a "Mãe Preta" foi também representada no jornal O Exemplo como naturalmente conformada com seu mundo de privações e impotente diante das "durezas do cativeiro". Ela suportava naturalmente o martírio e a dor:

${ }^{5}$ O Exemplo, 13 de maio de 1928, p. 1. 
Foi escrava. Passou por todas as provações, por todos os martírios e por todas as durezas do cativeiro. Devia ser por isso má e perversa, cheia de ódio contra a raça escravizadora. Não o foi, porém. Soube apesar de tudo amar e querer bem a quem lhe tirara o direito de ser livre. Trabalhou e sofreu. Pela dor dignificou-se, tornou-se grande e heroica, suportou o martírio e conquistou a veneração do Brasil (...). Este Brasil saberá perpetuar a memória da Mãe Preta num monumento digno e eterno. ${ }^{6}$

Nesse sentido, no contexto das relações raciais no Brasil na década de 1920, as narrativas em defesa da construção do monumento à "Mãe Preta” produziram um efeito pedagógico: construir um monumento para reverenciar simbolicamente a memória de todos aqueles que, como a "Mãe Preta", suportaram com passividade e submissão os martírios do cativeiro, apontando lugares subalternos para os corpos femininos negros. Conforme apontaram Gomes e Miranda (2014), o cenário de hierarquização que articula gênero e raça incide diretamente sobre os corpos e ensina como posicioná-los em meio a regras que produzem o corpo do homem como o normal e o corpo feminino como o dependente e subalterno.

É interessante destacar que outros documentos, além do jornal aqui retratado, apontam para a permanência da condição social do período da escravatura entre as mulheres negras nas primeiras décadas do século XX (RAGO, 1997). Estatísticas provenientes de documentos oficiais e de autoridades policiais retratam um grande número de mulheres negras e mulatas exercendo atividades de empregada doméstica, lavadeira, cozinheira e doceira. Pode-se compreender que a designação das mulheres negras para os serviços domésticos está associada ao longo período de escravidão pelo qual nosso país passou, e ainda pela "posterior marginalização social após a abolição” (GOUVEA, 2004, p. 230).

${ }^{6}$ O Exemplo, 13 de maio de 1928, p. 3. 
Por outro lado, conforme apontou Alberto (2011), a passividade e submissão da "Mãe Preta" eram atributos que interessava aos intelectuais brancos enfatizar após o desencantamento com os trabalhadores imigrantes estrangeiros, que, a partir do início do século XX, começaram a protestar contra seus patrões durante os movimentos grevistas. Nesse sentido, os intelectuais e políticos brancos que apoiaram a ideia do monumento à "Mãe Preta" pretendiam que ele servisse pedagogicamente, como modelo de submissão e fidelidade, aos trabalhadores e trabalhadoras nacionais afrodescendentes.

No entanto, as narrativas da "Mãe Preta" no jornal O Exemplo revelaram também o que Hall (1995) aponta como o modo negociado de apropriação das narrativas hegemônicas, no qual o receptor adapta a mensagem e até se opõe a ela parcialmente. Observa-se que a imagem da "Mãe Preta" foi apropriada pelos redatores d’O Exemplo para tecer críticas ao preconceito racial e à ausência de direitos dos negros na sociedade brasileira daquela época. Na narrativa construída por Mário Rodrigues, a "Mãe Preta" foi representada como "injustiçada por mesquinhos preconceitos de raça, proscrita das leis, sem direitos"7. Nesse sentido, construiu-se a noção de que o monumento significaria o reconhecimento de uma dívida da nação não somente para com a "Mãe Preta”, mas também para "com os africanos que outrora - há bem pouco tempo! - nas nossas lavouras sustentaram com mão de ferro, a riqueza econômica do Brasil e das mulheres africanas, cujos seios opulentos (...) fizeram o esplendor de quantos destinos" ${ }^{8}$. Produzia-se a noção de que a construção do monumento cumpria uma "dívida de gratidão" da nação para com os afro-brasileiros, o que implicava no reconhecimento das "injustiças" cometidas contra os negros, particularmente no mercado de trabalho, onde, na competição com os brancos, os negros frequentemente eram preteridos pelos trabalhadores imigrantes.

O Exemplo, 13 de maio de 1926, p. 3.

${ }^{s}$ Idem. 
Conforme aponta Andrews (1998), os imigrantes tinham preferência na contratação tanto nas cidades como no campo, e essa persistente preferência pelos europeus e euro-brasileiros afetava diretamente os afro-brasileiros, que passaram a se ressentir cada vez mais das severas restrições da República à participação política popular, o que levou a comunidade negra a expressar sentimentos de descontentamento e a pensar em formas de participação política. Nesse sentido, Alberto (2011) salientou que a retórica da contribuição do trabalho negro na década de 1920 era uma resposta construída pelos afrodescendentes à discriminação dos nacionais - representados de forma negativa, preconceituosa e pejorativa - no mercado de trabalho e à preferência pelos imigrantes europeus, continuamente retratados como bons trabalhadores.

Em novembro de 1926, O Exemplo reproduziu na primeira página, sob o título "O monumento da gratidão nacional”, o discurso dirigido pelo deputado federal do Rio Grande do Norte Georgino Avelino ao presidente da Câmara, concitando-o a apoiar a iniciativa do jornal A Notícia para a construção de um monumento à "Mãe Preta". O discurso foi reproduzido com uma pequena introdução do jornal O Exemplo, que o apresentava como "o sentimento da nossa gente". O deputado Avelino, ao longo do discurso, constrói a noção de uma "raça brasileira", "nova e pujante", formada pela integração de "raças estranhas" que imprimiram a "fisionomia típica e particular da nação". Para Georgino Avelino:

Foi nos pontos de atividades, constituído pelas fazendas e pelos engenhos, nesses pontos de centralização de homens de várias cores e estaturas, hábitos, línguas e ideologias que o espírito das três raças estranhas pela primeira vez gerou a alma da nova raça brasileira, que imprime fisionomia típica e particular a nossa evolução coletiva. ${ }^{9}$

Reproduzimos, a seguir, a primeira página do jornal O Exemplo com a reportagem "O monumento da gratidão nacional", referindo-se ao monumento à "Mãe Preta”.

9 O Exemplo, 7 de novembro de 1926, p. 1. 


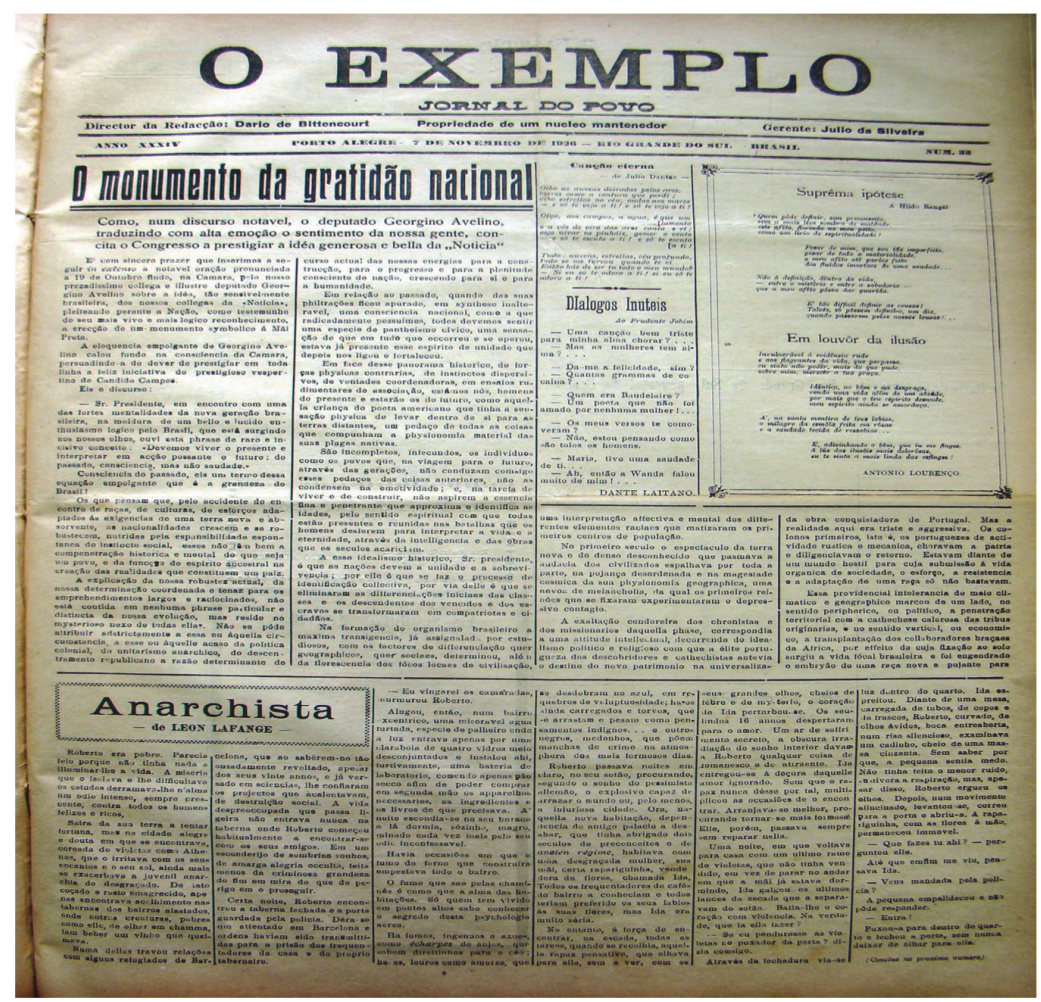

Figura 1. Capa do jornal O Exemplo.

Fonte: O Exemplo, 7 de novembro de 1926.

O deputado Avelino acrescentava à ideia de uma nova raça brasileira a noção de um espírito brasileiro, no qual as três raças, brancos, negros e indígenas, conviveriam sem hierarquias, antecipando, assim, a noção de democracia racial já em meados dos anos 1920:

A diferença das hierarquias sociais pelas quais se achavam distribuídas em proporções diferentes os diversos grupos étnicos foi anulada pela definição inalterável do tipo espiritual brasileiro, em cuja fisionomia, brancos, pretos e selvícolas se reconhecem condensados em um parentesco indissolúvel. ${ }^{10}$

10 Idem. 
Vale destacar que o contexto histórico da década de 1920 foi marcado também pela presença de um emergente nacionalismo cultural pós Primeira Guerra Mundial, pela participação de trabalhadores imigrantes em movimentos operários, reivindicando melhores condições de trabalho, e pelas manifestações da Semana de Arte Moderna em defesa de uma cultura nacional, que, juntos, contribuíram para impulsionar um orgulho nacionalista entre pensadores brasileiros, que começaram a repensar a relação entre a população racialmente diversa e a identidade nacional. Entre esses intelectuais, destaca-se Oswald de Andrade, que, no Manifesto Antropofágico, retratou a moderna cultura brasileira como o resultado da capacidade do nativo canibalizar e digerir as influências estrangeiras e produzir uma nova e autêntica identidade nacional. Nesse contexto de um nacionalismo emergente, políticos como o deputado Avelino passaram a relativizar a importância do trabalho do imigrante e a valorizar o trabalho da chamada "raça preta", como se pode observar no excerto a seguir:

A integração da raça preta na história do Brasil não se fez só porque com a extinção da escravatura a tenhamos trazido a uma situação política de igualdade de direitos. Incineramos os documentos relativos à escravidão, mas aceitamos com satisfação subalterna que nos afirmem que o surto industrial brasileiro provém dos italianos, dos alemães, dos espanhóis que colaboram conosco para elevar o padrão de nosso trabalho e da nossa produção, quando as riquezas ainda são basicamente as culturas antigas que os brasileiros estabeleceram com o concurso do escravo amigo e fiel. ${ }^{11}$

Nas narrativas construídas em torno da construção do monumento, as diferenças de gênero se somaram às diferenças étnico-raciais nas representações da "Mãe Preta". Hall (2000) argumenta que o fato visível de diferença étnico-racial também se manifesta na diferença sexual e destaca, ainda, a importância dos estudos de gênero como movimentos que têm gerado grande impacto nas esferas acadêmicas e sociais, possibilitando problematizar concepções dadas como universais, especialmente aquelas que definem o que é "próprio" para homens e para mulheres. Também Guizzo (2011) ressalta a contribuição dos estudos

${ }^{11}$ O Exemplo, 14 de novembro de 1926, p. 2. 
de gênero para relativizar, tencionar e problematizar as questões relacionadas às diferenças atribuídas às mulheres e aos homens, tomadas por muitos (as) estudiosos(as) como algo "naturalmente" dado e não como culturalmente constituído.

No entanto, observa-se que as representações de gênero mais recorrentes sobre a "Mãe Preta" que circularam no jornal O Exemplo mantiveram uma noção de feminilidade naturalizada, associando a mulher negra a papéis e atributos considerados femininos, tais como: maternidade, doçura e delicadeza. Enquanto o homem negro era associado ao trabalho, atribuía-se à mulher negra o papel de maternidade e reprodução da espécie, mesmo que elas tenham mantido a mesma rotina de trabalho dos homens escravizados nas lavouras de cana-de-açúcar e de café no Brasil entre os séculos XVI e XIX. A fim de problematizar tais representações, pensamos ser importante trazer as palavras de Soihet (1997), pesquisadora de gênero alinhada às teorizações críticas. Compreendemos que as mulheres de classes populares (livres) e as mulheres negras (escravas e libertas)

não se adaptavam às características dadas como universais ao sexo feminino: submissão, recato, delicadeza, fragilidade. Eram mulheres que trabalhavam e muito, em sua maioria, não formalmente casadas, brigavam na rua, pronunciavam palavrões, fugindo, em grande escala, aos estereótipos atribuídos ao sexo frágil (SOIHET, 1997, p. 367).

No entanto, observa-se também que o monumento foi reinterpretado pelos redatores d'O Exemplo, que selecionaram como representação visual da "Mãe Preta" uma imagem diferente da iconografia tradicional. Enquanto a imagem dominante apresentava a "Mãe Preta" somente com a criança branca, aquela veiculada pelo jornal, acrescentava a imagem da criança negra, posicionada aos pés da "Mãe Preta", enquanto a criança branca era amamentada. Portanto, na imprensa negra, as memórias da "Mãe Preta" foram simbolicamente construídas associadas à lembrança da dor e do sofrimento daquelas mães, que eram obrigadas a alimentar os filhos de suas senhoras brancas e a deixar seus próprios filhos sem alimento. 


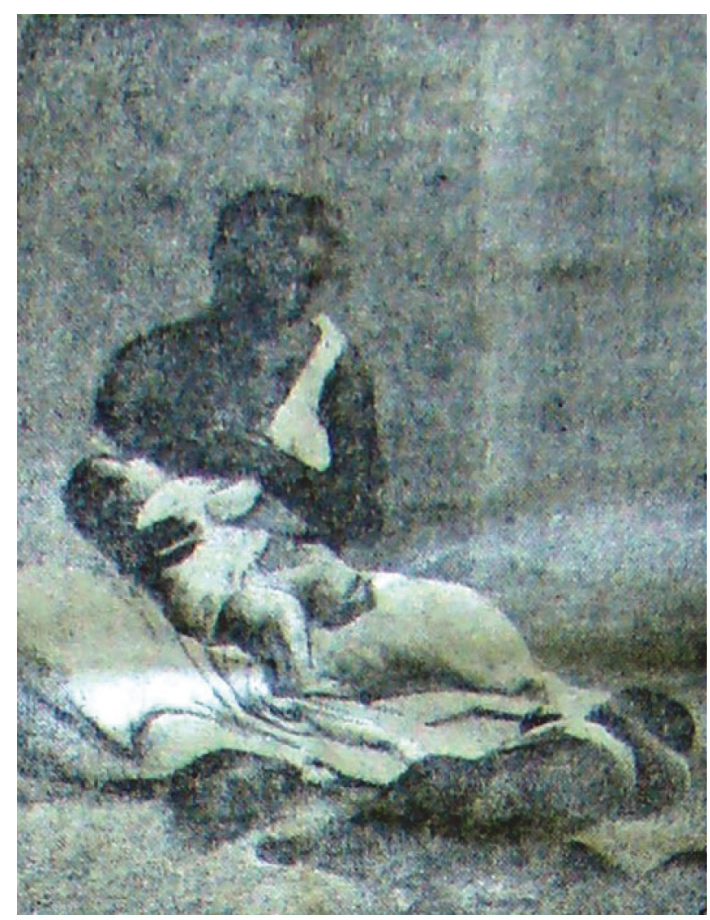

Figura 2. A "Mãe Preta”.

Fonte: O Exemplo, 13 de maio de 1926.

\section{Considerações finais}

No contexto das relações raciais no Brasil na década de 1920, os redatores do jornal O Exemplo se apropriaram das narrativas da campanha nacional em prol da construção de um monumento para a "Mãe Preta” disseminadas em outros jornais, particularmente A Notícia, do Rio de Janeiro, ora reproduzindo, ora negociando significados hegemônicos. Nesse sentido, não só adaptaram as narrativas hegemônicas sobre a "Mãe Preta" para incluir críticas aos preconceitos étnico-raciais, como associaram o simbolismo do monumento às contribuições dos afrodescendentes - cujos membros tinham trabalhado lado a lado para construir a grandeza do Brasil - para a identidade brasileira, salientando as contribuições positivas da presença negra na nacionalidade e tencionando a ideologia do branqueamento. 
Por outro lado, os jornalistas d'O Exemplo, ao representarem o Brasil como um lugar onde brancos e negros, por meio de suas relações compartilhadas com uma "Mãe Negra" simbólica, eram irmãos, também anteciparam as noções de democracia racial, construídas de forma mais sistemática na década de 1930. Portanto, como já apontaram Seigel (2009) e Alberto (2011), os significados de raça estavam sendo negociados e redefinidos na década de 1920, como bem evidencia a troca de ideias entre os jornais.

Nesse sentido, concordamos com Stuart Hall quando afirma que, na diáspora negra, houve apropriação, cooptação e rearticulação seletiva de ideologias e culturas, junto à preservação de tradições africanas (HALL, 2003). Hall argumenta que, na lógica cultural diaspórica, não existem formas culturais puras, mas formas hibridizadas, mistura de ideias, confluências de mais de uma tradição cultural, negociações entre posições dominantes e subalternas. Assim, se, por um lado, registra-se na campanha ao monumento à "Mãe Preta" uma continuidade das representações hegemônicas de gênero disseminadas na grande imprensa carioca e na imprensa negra paulista, por outro, observa-se a construção de novos projetos que tomaram como referência as necessidades de inclusão social e a defesa dos direitos da comunidade afrodescendente. Além disso, a imagem da "Mãe Preta" na imprensa branca do Rio de Janeiro foi negociada e redirecionada pela imprensa negra de Porto Alegre de modo a incluir, entre as suas representações imagéticas, o sofrimento das "mães pretas", que tiveram de abandonar seus próprios filhos em prol dos filhos alheios.

\section{REFERÊNCIAS}

ALBERTO, P. Terms of Inclusion: Black Intellectuals in Twentieth-Century Brazil. Chapel Hill: The University of North Carolina Press, 2011.

ANDREWS, G. R. Negros e brancos em São Paulo (1888-1998). Bauru, SP: EdUSC, 1998. 
CHARTIER, R. À beira da falésia: a história entre certezas e inquietudes. Porto Alegre: UFRGS, 2002.

GOMES, N. N.; MIRANDA, S. A. Gênero, Raça e Educação: indagações advindas de um olhar sobre uma academia de modelos. POIÉSIS, v. 8, n. 13, p. 91-111, 2014.

GOUVEA, M. C. S. Imagens do negro. In: GOUVEA, M. C. S. O mundo da criança: a construção do infantil na literatura brasileira. Bragança Paulista: Editora Universitária São Francisco, 2004.

GUIZZO, B. S. "Aquele negrão me chamou de leitão": representações e práticas corporais de embelezamento na educação infantil. 2011. 19lf. Tese (doutorado em Educação) - Programa de Pós-Graduação em Educação, Faculdade de Educação, Universidade Federal do Rio Grande do Sul, Porto Alegre, 2011.

HALL, S. Encoding, Decoding. In: DURING, Simon (Ed.). The Cultural Studies Reader. Londres: Nova York: Routledge, 1995.

HALL, S. The Spectacle of the 'Other'. In: HALL, S. Representation, Cultural Representations and Signifying Practices. Londres: Sage: Open University, 1997.

HALL, S. Identidades Culturais na Pós-Modernidade. 11. ed. Rio de Janeiro: DP\&A, 2000.

HALL, S. Que "negro” é esse na cultura negra? In: HALL, S. Da Diáspora: identidades e mediações culturais. Org. Liv Sovik. Belo Horizonte: UFMG; Brasília: Unesco, 2003. MAIGRET, É. Sociologia da comunicação e das mídias. São Paulo: Senac, 2010.

PELEGRINI, S. O patrimônio cultural e a materialização das memórias individuais e coletivas. Patrimônio e Memória, v. 3, n.1, 2007, p.87-100.

PEREIRA, A. A. Mundo Negro: relações raciais e a constituição do movimento negro contemporâneo no Brasil. Rio de Janeiro: Pallas: Faperj, 2013.

RAGO, M. Trabalho feminino e sexualidade. In: DEL PRIORE, Mary (Org.). História das mulheres no Brasil. São Paulo: Contexto, 1997.

SANTOS, J. A. Prisioneiros da História. Trajetórias Intelectuais na Imprensa Negra Meridional. 2011. 281f. Tese (doutorado em História) - Faculdade de Filosofia e Ciências Humanas da Pontifícia Universidade Católica do Rio Grande do Sul, Porto Alegre, 2011. SEIGEL, M. Uneven Encounters Making Race and Nation in Brazil and the United States. Durham: Londres: Duke University Press, 2009.

SOIHET, R. Mulheres pobres e violência no Brasil urbano. In: DEL PRIORE, Mary (Org.). História das mulheres no Brasil. São Paulo: Contexto, 1997.

ZUBARAN, M. A. Comemorações da liberdade: lugares de memórias negras diaspóricas. Anos 90, Porto Alegre, v. 15, n. 27, p. 161-187, 2008.

Data de submissão: 03/07/2015

Data de aceite: 02/11/2015 